\title{
PERAN MAGNETIC RESONANCE IMGAGING DALAM DIAGNOSIS DAN PROGNOSIS CEDERA MEDULA SPINALIS AKUT
}

\author{
THE ROLE OF MAGNETIC RESONANCE IMGAGING IN DIAGNOSIS AND \\ OUTCOME PREDICTION OF SPINAL CORD INJURY
}

\begin{abstract}
Reyhan Eddy Yunus, ${ }^{*}$ Taufik Budianto, ${ }^{*}$ Trifonia Pingkan Siregar, ${ }^{*}$ Thariqah Salamah,* Ramdinal Aviesena Zairinal, ${ }^{* *}$ Mohammad Triadi Wijaya***
\end{abstract}

\begin{abstract}
Spinal cord injury is a common type of injury that can be highly fatal. Clinically, spinal cord injury can be assessed using standardized physical examination scoring from International Standards for Neurological and Functional Classification of Spinal Cord Injury Patients, which is the American Spinal Injury Association (ASIA) impairment scale or often called as AIS. The results of this scoring will then be combined with magnetic resonance imaging (MRI) examination to determine the diagnosis and prognosis. In this case, we report a 20-year-old male complaining weakness in four extremities after traffic accident while driving a motorcycle. Based on neurological examination, the patient can barely feel a touch sensation and cannot move both his arms and legs at all. Cervical X-ray examination showed dislocation fracture on C5 level. Further MRI examination showed edema and spinal cord hemorrhage around fracture area. The findings of edema and spinal cord hemorrhage on MRI examination are useful in diagnosing and predicting the outcome of patient with spinal cord injury.
\end{abstract}

Keywords: AIS score, MRI, spinal cord injury

\section{ABSTRAK}

Cedera atau trauma medula spinalis merupakan salah satu jenis cedera yang sering ditemui dan dapat berakibat fatal. Secara klinis, cedera medula spinalis dapat dinilai dengan pemeriksaan fisis terstandar dari International Standards for Neurological and Functional Classification of Spinal Cord Injury Patients yaitu panduan American Spinal Injury Association (ASIA) impairment scale atau biasa disebut AIS. Hasil pemeriksaan dari skor AIS yang dihubungkan dengan pemeriksaan MRI untuk menegakkan diagnosis dan menetukan prognosis pasien. Pada kasus ini akan dilaporkan pasien laki-laki usia 20 tahun datang ke IGD rumah sakit dengan keluhan kelemahan keempat anggota gerak setelah mengalami kecelakaan lalu lintas saat sedang mengendarai sepeda motor. Pada pemeriksaan neurologis pasien masih dapat merasakan sedikit sentuhan namun tidak menggerakkan keempat ekstremitas sama sekali. Pemeriksaan $X$-ray servikal menunjukkan adanya fraktur dislokasi setinggi C5. Pemeriksaan MRI menunjukkan fraktur dislokasi setinggi C5 disertai edema dan perdarahan medula spinalis. Temuan edema dan perdarahan medula spinalis pada pemeriksaan MRI bermanfaat dalam proses diagnosis serta menentukan prognosis pasien dengan cedera medula spinalis akut.

Kata kunci: Cedera medula spinalis, MRI, skor AIS

\footnotetext{
*Departemen Radiologi, Fakultas Kedokteran Universitas Indonesia - Rumah Sakit Universitas Indonesia, Depok, Indonesia; **Departemen Neurologi, Fakultas Kedokteran Universitas Indonesia - Rumah Sakit Universitas Indonesia, Depok, Indonesia; ***Departemen Orthopaedi dan Traumatologi, Fakultas Kedokteran Universitas Indonesia - Rumah Sakit Universitas Indonesia, Depok, Indonesia. Korespondensi: reyhanyunus@ui.ac.id
}

\section{PENDAHULUAN}

Cedera atau trauma medula spinalis merupakan salah satu jenis cedera yang sering ditemui, dengan perkiraan 11.000 kasus baru pertahunnya. Cedera medula spinalis dapat terjadi pada daerah servikal dan torakolumbal. Beberapa penyebab terjadinya cedera ini adalah kecelakaan kendaraan bermotor, jatuh dari ketinggian dan luka tembak.

Secara klinis, cedera medula spinalis dapat dinilai dengan menggunakan pemeriksaan fisis terstandar dari International Standards for Neurological and
Functional Classification of Spinal Cord Injury Patients yaitu panduan American Spinal Injury Association (ASIA) impairment scale atau biasa disebut AIS. ${ }^{1}$ Panduan AIS berguna untuk menilai fungsi sensoris dan motoris pada pasien dengan cedera medula spinalis. Hasil dari setiap pemeriksaan dijabarkan pada formulir AIS dalam bentuk skala dan dikategorikan dalam skor ASIA. Terdapat 5 kategori skor ASIA, yaitu ASIA A yang merupakan cedera komplit, ASIA B, C dan D yang merupakan cedera inkomplit dan ASIA E yang masuk dalam kategori normal. ${ }^{1}$ 


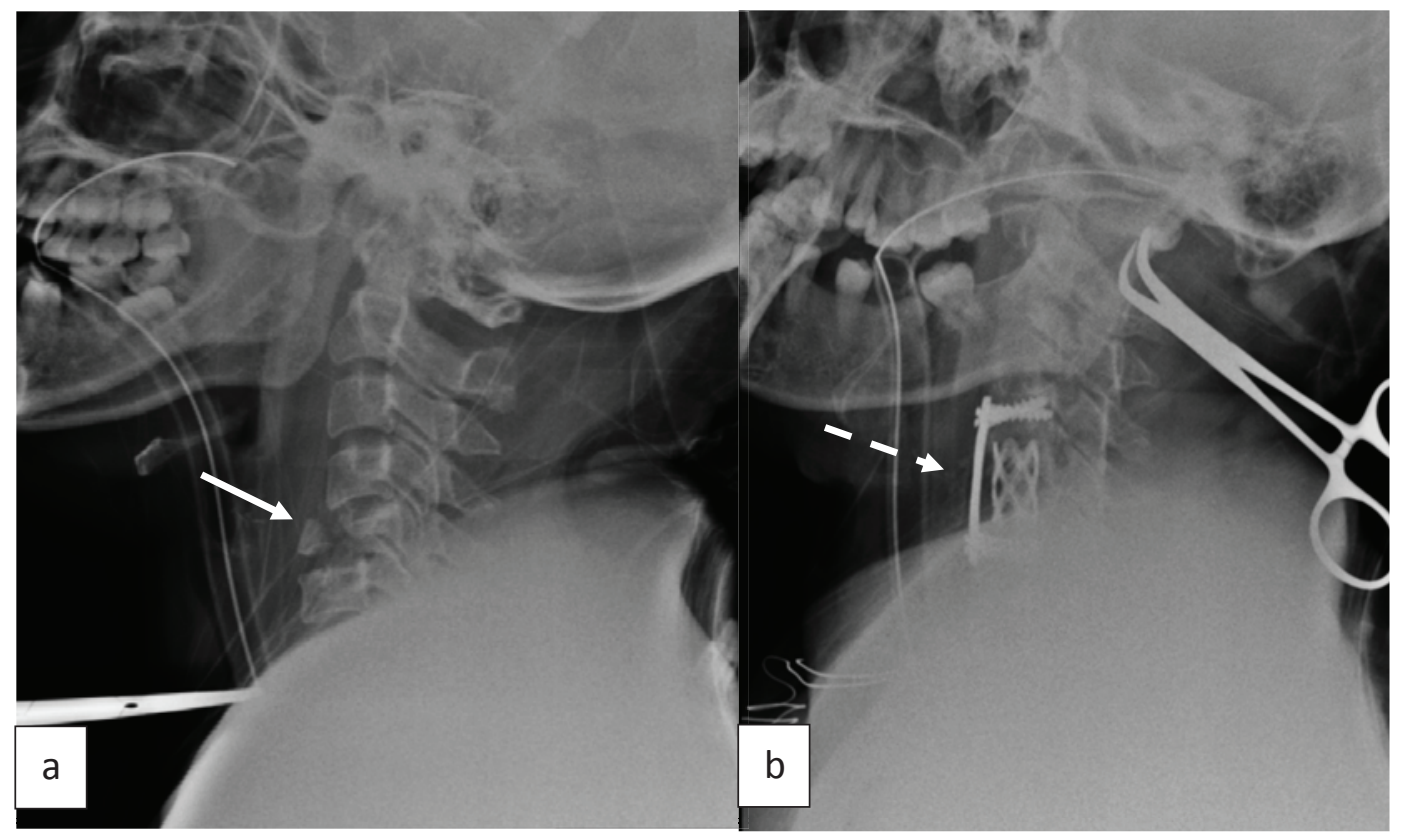

Gambar 1. X-ray Servikal Proyeksi Lateral Sebelum (a) dan Sesudah Operasi (b).

Panah putih tebal menunjukkan fraktur dislokasi C5 dengan pergeseran ke posterior. Panah garis putus menunjukkkan vertebra servikal pasca operasi anterior cervical corpectomy and fusion ACCF dengan kedudukan vertebra yang segaris.

Selain dari pemeriksaan fisis, pemeriksaan penunjang sangat penting dalam diagnosis cedera medula spinalis. Pemeriksaan radiologi seperti X-ray konvensional, CT-scan dan MRI merupakan modalitas pilihan pada pasien dengan cedera medula spinalis. Saat ini MRI menjadi pilihan utama pada cedera medula spinalis akut dikarenakan sensitivitas yang tinggi pada jaringan lunak dan dapat memprediksi perkembangan status neurologis pasien.,3 Tidak hanya itu, beberapa penelitian menyatakan bahwa penilaian klinis berdasarkan skor AIS dan gambaran pada MRI memiliki peran penting dalam menentukan prognosis pasien. ${ }^{4}$ Laporan kasus ini akan membahas peran MRI sebagai alat untuk diagnosis dan prognosis pada pasien dengan cedera medula spinalis akut.

\section{KASUS}

Pasien laki-laki usia 20 tahun datang ke IGD rumah sakit dengan keluhan kelemahan akut keempat anggota gerak akut setelah mengalami kecelakaan sepeda motor. Pasien sempat pingsan sesaat kemudian merasakan kelemahan keempat anggota gerak, rasa tebal dan kesemutan. Saat berada di rumah sakit, kelemahan anggota gerak dirasakan menetap sejak terjatuh. Pasien muntah 1 kali dan tidak didapatkan adanya penurunan kesadaran.
Berdasarkan pemeriksaan fisis pasien sadar penuh dengan skor Glasgow Coma Scale (GCS) 15, tekanan darah $80 / 60 \mathrm{mmHg}$ dan tanda vital lainnya dalam batas normal. Pada pemeriksaan neurologis pasien masih dapat merasakan sedikit sentuhan, namun tidak dapat menggerakkan keempat ekstremitas sama sekali. Pada saat colok dubur, terdapat kontraksi volunter otot sfingter ani eksterna (motor sacral sparing). Berdasarkan pemeriksaan klinis, pasien tergolong kategori skor ASIA B. Pasien didiagnosis dengan syok spinal dan tetraplegia upper motor neuron (UMN) et causa cedera medula spinalis dan suspek fraktur vertebra servikal.

Pasien kemudian menjalani pemeriksaan $X$-ray servikal. Berdasarkan pemeriksaan didapatkan gambaran fraktur dislokasi setinggi C5 (Gambar 1). Pasien kemudian menjalani pemeriksaan lanjutan menggunakan MRI untuk melihat kerusakan pada jaringan lunak sekitar.

Berdasarkan hasil MRI, terlihat fraktur dislokasi C5 dengan pergeseran fragmen fraktur ke posterior yang menyebabkan penyempitan berat kanal spinal (Gambar 2). Didapatkan gambaran perdarahan pada daerah paravertebral anterior dan posterior serta retrofaring. Selain itu, didapatkan juga pendesakan medula spinalis setinggi level C5 


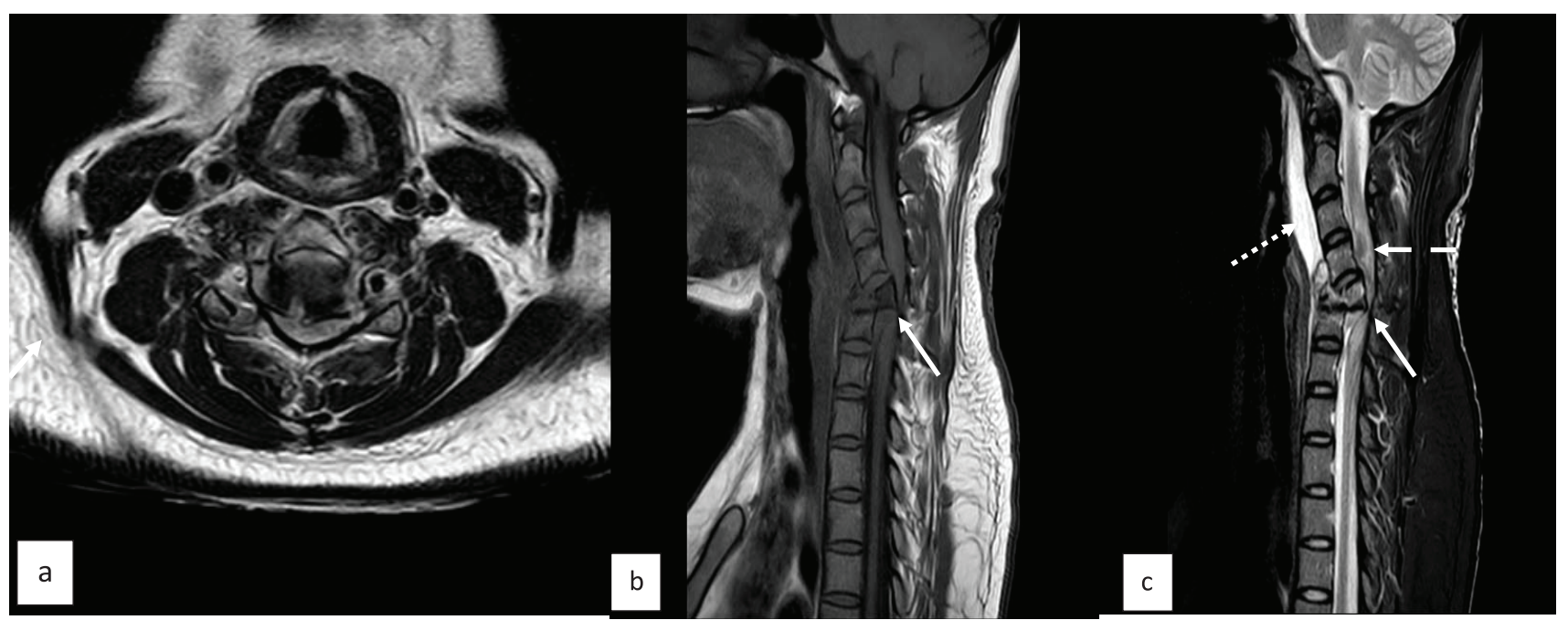

Gambar 2. Magnetic Resonance Imaging Servikal Sekuens T2W Potongan Aksial (a), T1 (b), dan T2

(c) Potongan Sagital.

Panah garis tebal menunjukkan fraktur dislokasi C5 dengan pergeseran ke posterior dan menyebabkan stenosis kanal berat dan penekanan medula spinalis level tersebut. Panah garis putus menunjukkan edema medula spinalis dan sebagian isointens T1W, hipointens T2W yang dapat menggambarkan perdarahan medula spinalis. Panah titik-titik menunjukkan menunjukkan perdarahan paravertebral dan retrofaring.

disertai gambaran edema dengan intensitas sinyal inhomogen berukuran $5 \mathrm{~cm}$ dan perdarahan medula spinalis berukuran $2 \mathrm{~cm}$.

Pasien kemudian menjalani operasi anterior cervical corpectomy and fusion (ACCF) 3 hari pasca kecelakaan untuk menangani fraktur servikal. Pasien meninggal 3 minggu pasca operasi pada saat perawatan di ICU karena gagal napas.

\section{PEMBAHASAN}

MRI merupakan modalitas radiologi terbaik untuk menilai cedera medula spinalis dikarenakan kemampuannya untuk mendeteksi edema medula spinalis, kontusio dan perdarahan, yang merupakan faktor-faktor penting untuk menegakkan diagnosis dan menentukan prognosis pasien.,3 Terdapat beberapa penelitian yang menyatakan pentingnya temuan edema dan perdarahan medula spinalis pada pemeriksaan MRI serta indikator-indikator lain yang menunjang.

Penelitian oleh Gupta $\mathrm{dkk}^{5}$ menyatakan bahwa maximum canal compromise (MCC), edema dan perdarahan medula spinalis merupakan komponen penting pada pemeriksaan MRI. Perdarahan medula spinalis merupakan indikator utama dalam menilai prognosis pasien dikarenakan adanya perdarahan mengindikasikan cedera yang komplit dan status neurologis yang buruk. ${ }^{5}$
Hasil ini didukung juga oleh Parashari $\mathrm{dkk}^{6}$ yang menyatakan perdarahan $>1 \mathrm{~cm}$ berkaitan dengan cedera yang komplit dan skor kekuatan motoris dan sensoris yang rendah pada skala AIS serta prognosis yang buruk $(\mathrm{p}<0,001)$. Pada penelitian ini disebutkan juga adanya edema medula spinalis, terutama dengan ukuran $>3 \mathrm{~cm}$ memiliki kemungkinan untuk sembuh 5,75 kali lebih kecil dibandingkan pada pasien tanpa adanya edema atau yang memiliki ukuran $<3$ cm. ${ }^{6}$ Namun, apabila pada pemeriksaan awal tidak didapatkan perdarahan maka perkembangan pasien akan lebih signifikan.

Penelitian lain oleh Miyanji $\mathrm{dkk}^{7}$ memiliki indikator yang lebih banyak untuk menilai derajat keparahan cedera medula spinalis. Indikator-indikator tersebut yaitu perdarahan, edema, cedera jaringan lunak, stenosis, herniasi diskus, panjang lesi, MCC dan maximum spinal cord compression (MSCC). Seluruh temuan ini dihubungkan dengan data dasar pemeriksaan pasien menggunakan skala AIS. Hasil penelitian ini menyatakan bahwa MCC $(\mathrm{p}=0,012)$, MSCC $(p=0,014)$ dan edema $(p<0,001)$ bermakna secara statistik untuk menilai tingkat keparahan cedera medula spinalis berdasarkan skor AIS. Untuk penilaian prognosis berdasarkan skor ASIA, indikator $\operatorname{MSCC}(p=0,028)$, perdarahan $(p<0,001)$ dan edema $(\mathrm{p}=0,029)$ bermakna secara statistik. 
Secara klinis pasien memiliki kelemahan, rasa tebal dan kesemutan pada keempat anggota gerak. Hal ini sesuai dengan penelitian oleh Parashari $\mathrm{dkk}^{6}$ yang menyatakan bahwa adanya perdarahan dan edema medula spinalis berkaitan erat dengan kelemahan sensoris dan motoris anggota gerak. Namun, berdasarkan skor AIS, pasien ini masih tergolong dalam skor ASIA B atau cedera inkomplit dikarenakan masih terdapat kontraksi volunter otot sfingter ani eksterna. ${ }^{7}$ Oleh karena itu, diperlukan pemantauan lebih lanjut pada pasien karena berdasarkan literatur adanya perdarahan $>1 \mathrm{~cm}$ dan edema $>3 \mathrm{~cm}$ mengindikasikan cedera komplit dan prognosis yang buruk. ${ }^{7}$

Pada kasus ini, pasien meninggal 3 minggu pasca operasi pada saat perawatan di ICU dengan penyebab kematian adalah gagal napas. Pasien telah dilakukan operasi ACCF dengan tujuan untuk mengevakuasi perdarahan paravertebral dan mengurangi penekanan medula spinalis. Tindakan ACCF dilakukan dengan mengganti corpus vertebra yang fraktur dengan graft dan memasang fiksasi interna berupa plat anterior untuk memperbaiki kesegarisan vertebra servikal. Kematian pada pasien ini dapat disebabkan awitan lambat cedera medula spinalis servikal yang berhubungan dengan kegagalan sistem pernapasan karena kelemahan otototot bantu napas. ${ }^{4}$

\section{KESIMPULAN}

MRI merupakan modalitas yang dapat digunakan untuk mendeteksi cedera medula spinalis akut. Adanya perdarahan dan edema berkaitan erat dengan status neurologis pasien yang buruk, cedera spinal komplit dan prognosis yang buruk.

\section{DAFTAR PUSTAKA}

1. Vyas NA, Teicher EJ, Griffen MM. Spine and Spinal Cord Injuries, dalam: Current Surgical Therapy. Edisi 12. Elsevier: USA; 2017. Hal: 1219-24.

2. Mahmood NS, Kadavigere R, Ramesh AK, Rao VR. Magnetic resonance imaging in acute cervical spinal cord injury: a correlative study on spinal cord changes and 1 month motor recovery. Spinal Cord. 2008 Dec;46(12);791-7.

3. Chandra J, Sheerin F, Lopez de Heredia L, Meagher T, King D, Belci M, dkk. MRI in acute and subacute post-traumatic spinal cord injury: pictorial review. Spinal Cord. 2012 Jan;50(1):2-7.

4. Matsushita A, Maeda T, Mori E, Yuge I, Kawano $\mathrm{O}$, Ueta T, dkk. Can the acute magnetic resonance imaging features reflect neurologic prognosis in patients with cervical spinal cord injury? Spine J. 2017 Sep;17(9):1319-24.

5. Gupta R, Mittal P, Sandhu P, Sanggar K, Gupta K. Correlation of Qualitative and Quantitative Mri Parameters with Neurological Status: A Prospective Study on Patients with Spinal Trauma. J Clin Diagn Res. 2014 Nov;8(11):RC13-7.

6. Parashari UC, Khanduri S, Bhadury S, Kohli N, Parihar A, Singh R, dkk. Diagnostic and prognostic role of MRI in spinaltrauma, its comparison and correlation with clinical profile and neurological outcome, according to ASIA impairment scale. J Craniovetebr Junction Spine. 2011;2(4):1-11.

7. Miyanji F, Furlan JC, Aarabi B, Arnold PM, Fehlings MG. Acute Cervical Traumatic Spinal Cord Injury: MR Imaging Findings Correlated with Neurologic Outcome-Prospective Study with 100 Consecutive Patients. Radiology. 2007;243(3):820-6. 